\title{
38. Dreiländertreffen in Innsbruck
}

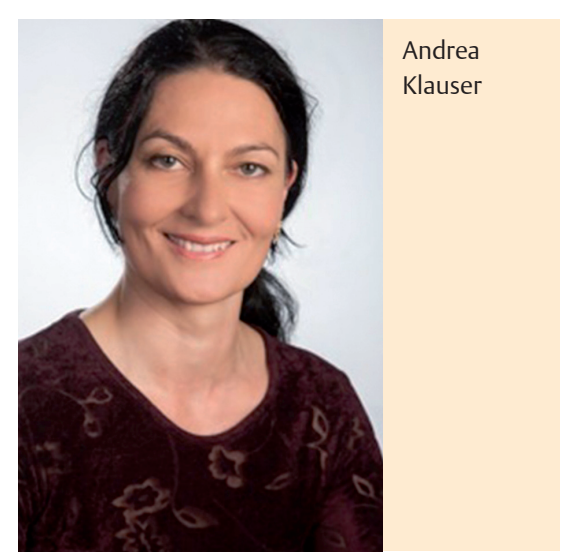

Sehr geehrte Kolleginnen und Kollegen!

Dieses Jahr wird das 38. Dreiländertreffen vom 29. bis 31. Oktober 2014 in Innsbruck stattfinden. In enger und intensiver $\mathrm{Zu}$ sammenarbeit mit den 2 Schwestergesellschaften ist ein ausgewogenes Fortbildungsprogramm vorbereitet worden. Das Programm können Sie auf der Website http://www.ultraschall2014.at einsehen. Es ist uns gelungen, 10 Anwenderseminare für den 1. Tag am Mittwoch zu organisieren, zu denen die Anmeldung bereits angelaufen ist, weiters werden hochkarätige Fortbildungen in 37 Refresherkurse und 10 Workshops angeboten.

Junge NachwuchswissenschaftlerInnen möchte ich an dieser Stelle herzlich einladen, wissenschaftliche Beiträge einzureichen, das Ende der Einreichfrist ist der 26. Mai. Um dies attraktiv zu gestalten, wird eine Prämierung der besten Arbeiten am Kongress erfolgen und der Zutritt zum Kongress ist für alle unter dem 36. Lebensjahr ohne Kongressgebühr.

Die Tagung wird im Zentrum der Stadt, im „Congress Innsbruck“ abgehalten. Innsbruck ist nicht nur Sport- und Tourismusstadt, sondern dank zahlreicher Bauten aus der Zeit Kaiser Maximilians I., und der einzigartigen Lage inmitten der Tiroler
Bergwelt bei Reisenden aus aller Welt ein sehr beliebtes Ziel. In nur 20 Minuten gelangen Sie vom Kongresszentrum mit der Nordkettenbahn in hochalpines Gelände. Die gesamte Anlage der Nordkettenbahn wurde von der weltbekannten Stararchitektin, Zaha Hadid, geplant und entworfen. Die Nordkettenbahn werden wir auf der Fahrt zum Gesellschaftsabend auf die Hungerburg nutzen, wo der 1. Kongresstag seinen Ausklang findet.

Aufgund der Nähe zu Allerheiligen am 1. November wird der diesjährige Kongress auf 3 Tage kondensiert, in denen dennoch ein höchst attraktives ansprechendes, reichhaltiges Programm angeboten werden wird.

Ich hoffe, Ihr Interesse nach Innsbruck zum 38. Ultraschall Dreiländertreffen zu kommen, geweckt zu haben, um Wissen und Fertigkeiten auszutauschen, Freunde zu treffen, und das Potenzial der Ultraschalldiagnostik weiter auszudehnen.

Ich freue mich sehr auf Ihre Teilnahme

Mit herzlichen Grüßen aus Innsbruck

Univ. Doz. Dr. Andrea Klauser 